\title{
Hyperbaric oxygen therapy: a key role in the treatment of cerebral gas embolism
}

\begin{abstract}
Stroke is an important cause of morbidity and mortality. The etiologies are varied. Gas embolism is a known complication of invasive procedures, which may complicate with cerebral embolization and ischemia. Benefits of hyperbaric oxygen therapy are recognized in cerebral gas embolism when started in the first hours after the event, which are fundamental for the vital prognosis.
\end{abstract}

Keywords: cerebral gas embolism; hyperbaric oxygen therapy; stroke; patent foramen ovale

\section{CASE REPORT}

Introduction: Stroke is an important cause of morbidity and mortality. Early diagnosis and rapid etiological identification are fundamental for a timely treatment, in order to minimize possible neurological sequelae.

Clinical Case: A 63-year-old man, smoker, with lung injury under study was admitted for transthoracic aspiration biopsy (TAB). After the procedure, he suddenly had a cardiorespiratory arrest with electrical activity without a pulse. Immediatly advanced life support are started with recovery at the end of the first cycle. He was transported to the emergency room under invasive mechanical ventilation (IMV), but hemodynamically stable. Neurologically, he presented a conjugate deviation of the eyes to the right, a motor response in bilaterally extension, paratonia of the lower limbs and indifferent cutaneous-plantar reflexes. The etiological investigation concluded that it was a gas embolism (GE) in the territory of the right middle cerebral artery in a patient with an unknown patent foramen ovale (PFO). The patient was immediately transferred to the Hyperbaric Medicine Unit for treatment. He manteined IMV and intensive care hospitalization for 24 hours. At the time of discharge, he had left hemiparesis with face and grade $4+$ muscle strength.

Discussion: GE is an uncommon, potentially catastrophic event secondary to air entering the blood vessels (venous or arterial) ${ }^{1,2}$. The most common causes are surgeries, trauma, vascular procedures, barotrauma, and $\mathrm{TAB}^{2}$.

Smokers and patients with chronic obstructive pulmonary disease are risky groups.

PFO is a congenital anomaly with high prevalence in the adult population (20-25\%) 3 and the association with cryptogenic stroke $(40 \%)^{3}$ has been demonstrated.

Hyperbaric oxygen therapy is recommended in cases of GE with cardiorespiratory compromise, neurological deficits and / or target organ damage, and its benefit are described in the literature, mostly when initiated within the first 6 hours after the event ${ }^{4}$. It provides oxygen pressures above atmospheric pressure and $100 \%$ oxygen concentrations, leading to a "supra-physiological" systemic hyperoxia level, allowing large nitrogen gradients to be displaced from the interior of the air bubble, which, in turn, reduces its size (Boyle's Law) ${ }^{4}$. At pressures of $282 \mathrm{kPa}$, the diameter of the gas bubble is reduced to $82 \%$, resulting in a $45 \%$ decrease in volume and resolution of embolic phenomena ${ }^{4}$.

Conclusion: In this case, aifflow occurred in the systemic venous system, resulting from $T A B$, which is a rare complication $(0.02 \text { to } 0.06 \%)^{2}$, migrating to the arterial system through PFO, with embolization to the vasculature causing ischemia.
Figure 1. A: Cerebral CT with GE located in the cortical branches of the right middle cerebral artery. B: Cerebral MRI with small foci of acute ischemia at the pre-central, right frontal and right frontal gyri.
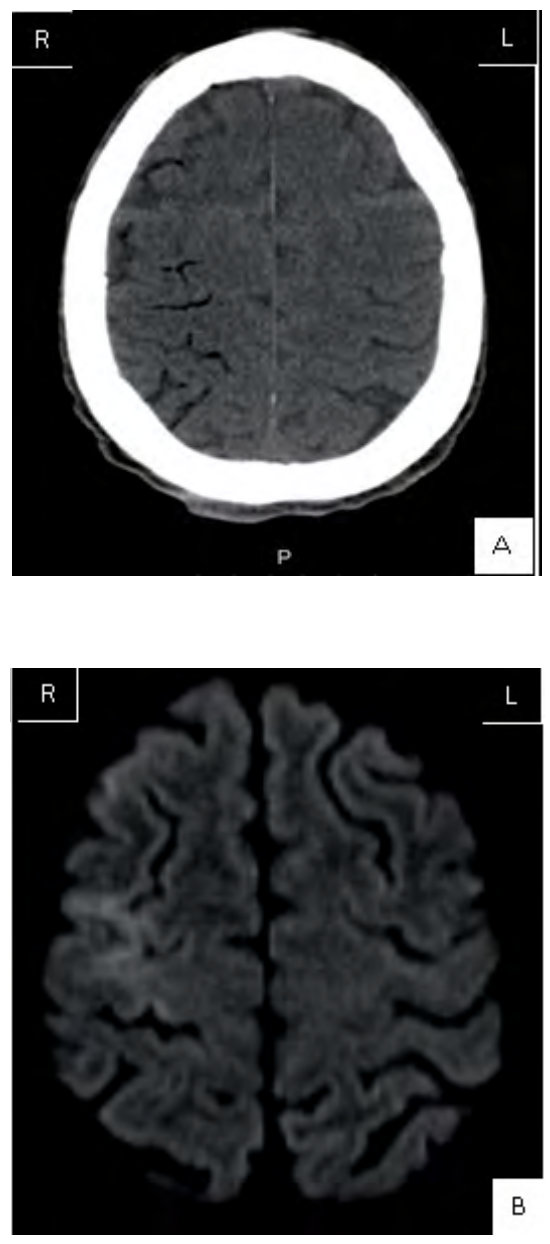

\section{BIBLIOGRAPHIC REFERENCES}

1 Muth CM, Shank ES. Gas embolism. N Engl J Med. 2000; 342:476-82.

2 Rahman ZU, et al. Cardiac Arrest as a Consequence of Air Embolism: A Case Report and Literature Review. Case Rep Med. 2016; 2016 (4).

3 J Am Coll. Cryptogenic stroke and Patent Foramen Ovale. Cardiol 2018; 71:10351043 Cryptogenic Stroke and Patent Foramen Ovale.

4 Rocco M, et al. Successful Treatment of Cerebral Arterial Gas Embolism Following Uneventful TBNA. J Pulm Respir Med. 2015; 5

\section{DIAGNOSIS}

\section{Cerebral gas embolism}

\author{
Fernandes $A \mathrm{M}^{1}$, Fonseca $\mathrm{T}^{1}$, Paixão $\mathrm{Al}^{2}$, Castelões $\mathrm{P}^{2}$ \\ ${ }^{1}$ Resident of Intensive Medicine, Intensive Care Service, Centro Hospitalar Vila \\ Nova Gaia/Espinho. \\ ${ }_{2}^{2}$ Intensivist, Intensive Care Service, Centro Hospitalar Vila Nova Gaia/Espinho \\ Correspondencia: amargaridafernandes03@gmail.com \\ Cómo citar este artículo: Fernandes AM, Fonseca', Paixão Al, Castelões P \\ Hyperbaric oxygen therapy: a key role in the treatment of cerebral gas embolism. Galicia Clin 2020; 81 (3): 96 \\ Recibido: 01/04/2019; Aceptado:02/04/2019 // http://doi.org/10.22546/57/1935
}

